\title{
Using 2-dimensional dispersal kernels to identify the dominant influences on larval dispersal on continental shelves
}

\author{
K. P. Edwards ${ }^{1,2, *}$, J. A. Hare ${ }^{3,4}$, F. E. Werner ${ }^{1}$, H. Seim ${ }^{1}$ \\ ${ }^{1}$ Department of Marine Sciences, University of North Carolina Chapel Hill, Chapel Hill, North Carolina 27599, USA \\ ${ }^{2}$ Romberg Tiburon Center for Environmental Studies, Tiburon, California 94920, USA \\ ${ }^{3}$ NOAA Beaufort Laboratory, 101 Pivers Island Road, Beaufort, North Carolina 28516, USA \\ ${ }^{4}$ NOAA NEFSC NMFS, Narragansett Laboratory, 28 Tarzwell Drive, Narragansett, Rhode Island 02882, USA
}

\begin{abstract}
Pelagic larval dispersal is thought to be the main mechanism connecting many marine populations and is an important determinant both of an individual's success and a population's distribution and spatial structure. Thus, quantitative estimates of the retention or dispersion of larvae from spawning grounds is important for the determination of recruitment success in fisheries. Models can be used to study connectivity through a dispersal curve or dispersal kernel: the probability that a larva will settle at a given distance from its release location. We applied a 3-dimensional circulation model and a Lagrangian particle tracking model to the southeast US continental shelf to describe dispersal kernels in 2 dimensions. We used a fully orthogonal design to assess the importance of factors that influence the dispersal kernel, including spawning time, spawning location, larval behavior (vertical position in the water column), larval duration, and turbulent dispersal. Our results indicate that adult behavior, in the form of spawning time and location, may be more important than larval behavior in determining larval dispersal on the inner- and mid-shelves in this region.
\end{abstract}

KEY WORDS: Dispersal kernels · Larval fish · Lagrangian particle tracking • Southeast US continental shelf

Resale or republication not permitted without written consent of the publishe

\section{INTRODUCTION}

Many marine populations are thought to be connected by a pelagic larval stage during which individuals are dispersed from spawning sites (Caley et al. 1996). This dispersal is an important determinant of both the survival of an individual and the distribution and spatial structure of a population (Nathan 2001, Cowen et al. 2006). Dispersal results from a complex interaction between physical and biological factors (Guichard et al. 2004) including spawning time, spawning location, advection, dispersion (or 'eddy diffusion'), planktonic duration, planktonic survival, and planktonic behavior (Hare 2005 and references therein). Spawning time and location initiates the transport process, while planktonic duration determines the time over which dispersal occurs. Advection and dispersion transport individuals from spawning locations over the duration of the planktonic period. In a flow field with vertical differences in current speed and direction, vertical position is important to the outcome of transport and thus vertical advection, egg and larval buoyancy, and larval swimming influence dispersal (Werner et al. 1993). Survival of the eggs and larvae also is an important factor in dispersal and is affected by the environment (such as temperature), feeding conditions, and predation (Bailey \& Houde 1989). Finally, the distribution of juvenile habitat is used to distinguish actual planktonic transport from potential larval dispersal by including the successful arrival of larvae to juvenile habitat (Hare 2005).

In both marine and terrestrial systems, dispersal has been studied using several methods including genetic analyses, direct measurements of individual move- 
ment, and observations of the spatial distribution of larvae (Nathan 2001). Genetic methods relate mean dispersal distance to the increase in genetic differentiation with distance, or isolation-by-distance (IBD) (Kinlan \& Gaines 2003). However, genetic homogeneity only requires the exchange of a very few individuals such that, as with near-homogeneity, the genetic structure of many marine species is generally within the range of error (Shanks et al. 2003). The use of direct tracking of individual larvae remains difficult (see review by Thorrold et al. 2002), and has been accomplished for only a few species including tunicate larvae (Olson 1985) and hard clam larvae (Arnold et al. 2005). Observations of the spatial distribution of larvae can also be used to study dispersal (Cowen et al. 1993), but do not provide information about the transport paths of individual larvae and may not provide a link between the spawning location and juvenile habitat.

Given the difficulties and uncertainties with both genetic analysis and observations of larval dispersal in marine systems, modeling can be an important tool with which to track larvae from spawning to settlement and to infer patterns of larval dispersal (Werner et al. 2001). The simplest mathematical models estimate the extent of larval dispersal from the duration of the pelagic larval stage combined with the movement of passive particles in low-frequency currents (Grantham et al. 2003, Shanks et al. 2003 and references therein). Additional structure can be considered using 3-dimensional circulation models that include vertical turbu-

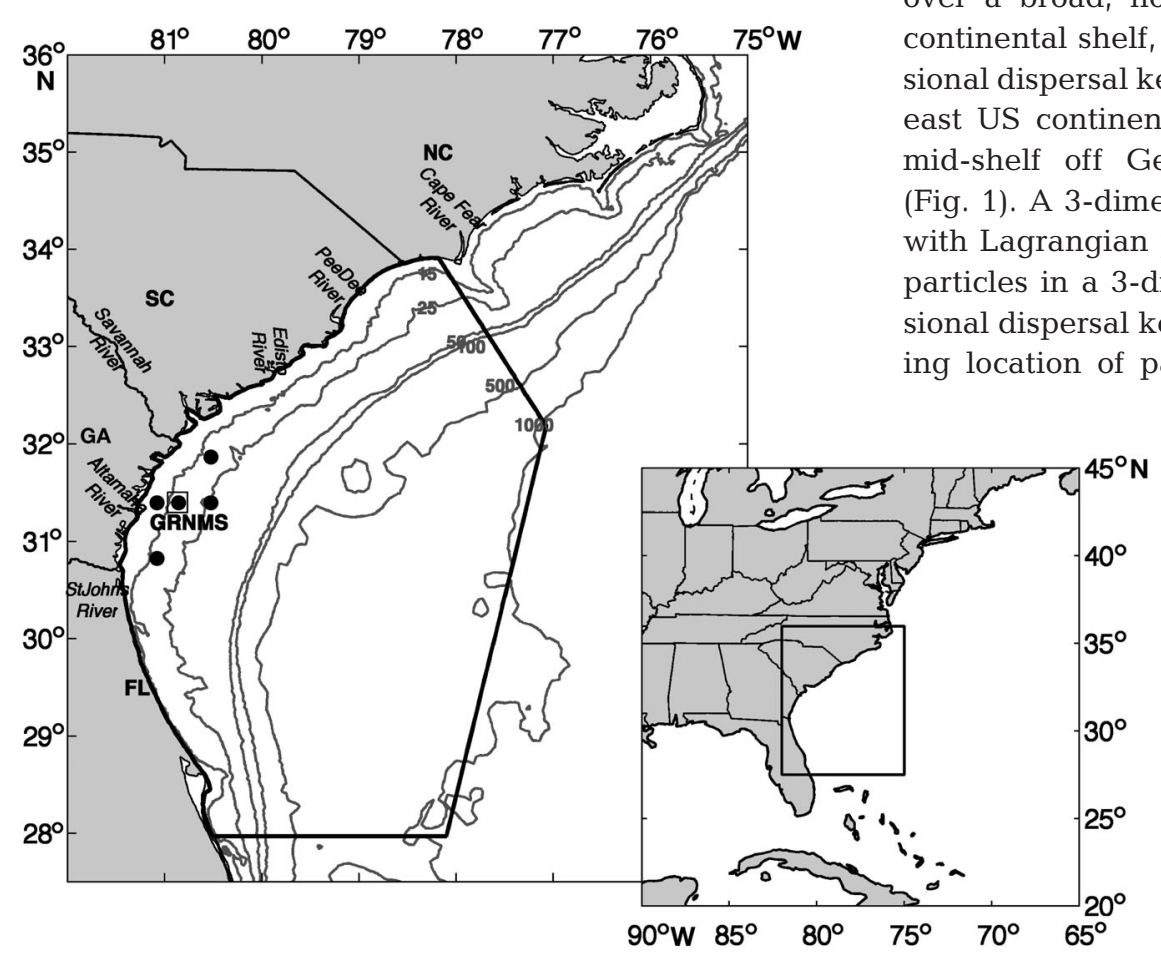

lence (Werner et al. 2001) as well as particle behaviors such as diel vertical migration (Hare et al. 1999) and horizontal swimming behavior (Werner et al. 1993). Settlement habitat can also be included to reflect the habitat requirements necessary for continuation of the life cycle (Paris et al. 2005). Finally, some studies follow larvae throughout their planktonic stage by coupling circulation and Lagrangian particle tracking models with individual-based larval models that either use a temperature-based growth model (Pedersen et al. 2003) or include a specific feeding environment for the target species (Werner et al. 2001).

One tool for quantifying larval dispersal is the dispersal curve or dispersal kernel, which is defined as the number of propagules per unit area as a function of the distance from its release location or the frequency distribution of dispersal distances (Nathan 2001). Dispersal kernels can be used to explore the complex interactions among the factors determining dispersal and to make predictions about which of these factors are most important. To date, most models that define dispersal kernels in oceanic regions have generally made simplifying assumptions, such as straight coastlines and passive larvae, and have used a 1-dimensional probability density function for the dispersal kernel (Siegel et al. 2003, Guichard et al. 2004). Where larval dispersal and settlement habitat are not limited to 1 dimension (e.g. broad continental shelves and islands), a 2-dimensional dispersal kernel is more appropriate.

Our aim was to examine which factors are most important in determining the dispersal of larvae spawned over a broad, horizontally and vertically structured continental shelf, requiring the definition of 2-dimensional dispersal kernels. The study area was the southeast US continental shelf, specifically the inner and mid-shelf off Georgia, where the shelf is widest (Fig. 1). A 3-dimensional circulation model combined with Lagrangian particle tracking was used to follow particles in a 3-dimensional flow field. The 2-dimensional dispersal kernels were calculated from the endrticles. The relative importance of various factors that affect this larval dispersal was examined using a fully orthogonal approach such

Fig. 1. Southeast US continental shelf and the model domain (NC: North Carolina; SC: South Carolina; GA: Georgia; FL: Florida). •: 5 release locations; $\square:$ center release location in Gray's Reef National Marine Sanctuary (GRNMS); $15,25,50,100,500$ and $1000 \mathrm{~m}$ isobaths are shown. Inset: eastern half of the US; the black box encloses the southeast US continental shelf 
that dispersal kernels were calculated using all combinations of the factors investigated. The effect of 5 factors was investigated: spawning time, spawning location, larval duration, larval behavior, and physical dispersion.

\section{MATERIALS AND METHODS}

Study region. The southeast US continental shelf (Fig. 1) extends from Cape Canaveral, Florida to Cape Hatteras, North Carolina and is narrowest at the northern and southern ends (10 to $30 \mathrm{~km}$ ) and widest in the center, off the coast of Georgia $(120 \mathrm{~km})$. The coast is punctuated with rivers and tidal inlets, particularly in South Carolina, Georgia and northern Florida, providing important juvenile habitat for many marine species. The shelf has been extensively studied (Boicourt et al. 1998 and references therein) and can be divided into 3 cross-shelf regions, each with a different primary driving mechanism (Boicourt et al. 1998). Circulation on the inner-shelf (from the coast to the $20 \mathrm{~m}$ isobath) is dominated by river discharge, atmospheric fluxes and tides; while on the mid-shelf (from the 20 to $45 \mathrm{~m}$ isobaths) circulation is driven primarily by the winds and influenced by the tides and the Gulf Stream; the outer-shelf is dominated by the Gulf Stream (Boicourt et al. 1998). With the circulation over inner- and midshelf regions being driven by the winds, circulation patterns change seasonally with seasonal transitions in the winds (Blanton et al. 1985, Blanton et al. 2003).

The focus of this study was the portion of the southeast US shelf off Georgia. There is interest in potentially developing marine protected areas (MPAs) in the region. Gray's Reef National Marine Sanctuary (GRNMS) is a small marine sanctuary off the coast of Sapelo Island, Georgia, located near the boundary between the inner and mid-shelf zones and with rocky-reef habitat typical of the shelf. An important aspect of designing a network of MPAs in this region is an understanding of the patterns of larval dispersal and connectivity among areas of spatially discrete reef habitats. The Lagrangian characteristics of this shelf were studied by Edwards et al. (2006) through a comparison between observed and numerical drifters. It was found that populations of marine organisms in the central mid-shelf might be relatively closed on the scale of 1 to 2 months, resulting in the retention of larvae off the coast of Georgia (Edwards et al. 2006). A probabilistic larval transport model based on drifters released off Georgia and Florida also indicated that the Georgia shelf is an area of retention (Hare \& Walsh 2007). The present study is a continuation of our efforts to understand larval dispersal in the region, and aims to identify which factors are most important in deter- mining the 2-dimensional dispersal kernel of larvae spawned on the southeast US shelf.

3-dimensional circulation model and Lagrangian particle tracking model. A highly resolved circulation model for the shelf region was used to model larval transport (Lynch \& Werner 1991, Greenberg et al. 1998). The flow fields used here represent the longterm monthly mean circulation (climatology) as described by Blanton et al. (2003) and the main tidal constituent in this region, the $M_{2}$ tide (Blanton et al. 2004). The monthly climatology includes both density and wind-driven flows derived from long-term data sets (temperature and salinity observations from 1975 to 1999 and Comprehensive Ocean-Atmosphere Data Set wind velocities from 1975 to 1999; Blanton et al. 2003). The model domain extends from south of Cape Canaveral, Florida to Cape Fear, North Carolina (Fig. 1). The model grid has 21 vertical levels and was run with a minimum bathymetric depth of $2 \mathrm{~m}$. Grid spacing is variable, with the smallest grid spacing in the order of $1 \mathrm{~km}$ nearest the coast increasing off-shore to the order of $10 \mathrm{~km}$.

Particles' 3-dimensional trajectories were computed using hourly values of the modeled flow field (as in Edwards et al. 2006 and references therein). The particle-tracking algorithm contains a provision for a horizontal turbulent kick to simulate diffusion using a Gaussian random flight process, with additional displacements ( $\delta x$ and $\delta y$ ) calculated from:

$$
(\delta x, \delta y)=\beta \sqrt{2\left(K_{x}, K_{y}\right) \Delta t}
$$

Here $\beta$ is a random deviate from a standard normal distribution (mean $=0$, variance $=1$ ), $t$ is time and $\Delta t$ is the time step. $K_{X}$ and $K_{Y}$ are eddy diffusivities in the east-west $(x)$ and north-south $(y)$ directions (Berg 1993), and are assumed to be constant in the present study, thereby justifying the use of a simple, uncorrected random walk method (Hunter et al. 1993). In ocean circulation modeling, 'diffusion' due to sub-gridscale processes (or processes not modeled) is often parameterized by an eddy diffusivity term to account for unresolved advective processes such as frontal instabilities and sea breezes, among others. The value of 'eddy diffusion' used in the present study was systematically varied as part of the examination of the effect of various factors on the 2-dimensional dispersal kernel (see below).

Particles were released at specific locations (see below) and then followed in the model; once particles hit the coastline, they remain there for the reminder of the release duration. At the end of the planktonic stage, particle locations were used to calculate dispersal kernels. Since the model included dispersion, particle transport had a random component and particles 
released at the same location could have different end points. Initially, model runs were made with 100, 200, $300,400,500$ and 1500 particles released at each location. In the runs with 300 or more particles, no significant differences in the dispersal kernel statistics were found, so 300 particles were released in each model run and used in the calculation of the dispersal kernels.

Definition of 2-dimensional dispersal kernel. The dispersal kernel is defined as the density of settling particles at a given location, normalized by the number of particles released. To assess larval dispersal in turbulent coastal flows, Siegel et al. (2003) used a 1-dimensional stochastic Lagrangian model. Their results indicated that the dispersal kernels are approximately Gaussian in form and suggested the following 3 parameters: amplitude, downstream drift $\left(\mathrm{x}_{d}\right)$, and spread $\left(\sigma_{d}\right)$.

To extend the definition of dispersal kernels to 2 dimensions, we used the following 5 parameters: mean distance dispersed $(d)$, direction of $d$ relative to starting location $(\theta$, degrees counterclockwise from East), variance of the major (maj) and minor (min) axes of the underlying population, and the principal angle $\left(\theta_{\mathrm{m}}\right)$, which is the orientation of the major axis (as shown in Fig. 2A).

The latter 3 parameters of the dispersal kernel were calculated using principal component analysis (PCA) from the ending positions of the particles in the model following Preisendorfer (1988). The principal angle $\theta_{\mathrm{m}}$ is the angle along which the variance $s^{2}(\theta)$ is a maximum. The second principal angle is at $\theta_{\mathrm{m}}+\pi / 2$. The 2 principal variances occur at the principal angles and are defined as $S_{11}=\int S_{S}^{2}\left(\theta_{\mathrm{m}}\right)$ and $S_{22}=\int S_{S}^{2}\left(\theta_{\mathrm{m}}+\pi / 2\right)$.

In terms of the original data

$$
\begin{gathered}
s_{11}=\frac{1}{2}\left\{\left(s_{X X}+s_{Y Y}\right)+\left[\left(s_{X X}+s_{Y Y}\right)^{2}+4 s_{X Y}^{2}\right]^{2}\right\} \\
s_{22}=\frac{1}{2}\left\{\left(s_{X X}+s_{Y Y}\right)-\left[\left(s_{X X}+s_{Y Y}\right)^{2}+4 s_{X Y}^{2}\right]^{2}\right\} \\
\theta_{\mathrm{m}}=\frac{1}{2} \arctan \left(\frac{2 s_{X Y}}{s_{X X}-s_{Y Y}}\right)
\end{gathered}
$$

where $s_{x x}$ and $s_{y y}$ are the variances of the original data set, and $s_{X y}$ is the covariance of the original data set. The size of the variance ellipse major and minor axes are then calculated as $\operatorname{maj}=\sqrt{s_{11}}$ and $\min =\sqrt{s_{22}}$.

Factors affecting dispersal kernels. Five factors were examined for their affect on the 2-dimensional dispersal kernels: release month, release location, larval duration, larval behavior, and the model's dispersion coefficient. A fully factorial modeling approach for these 5 factors was used, resulting in a total of 1620 model runs (Table 1). Particles were released in the model, subjected to the 3-dimensional flow field, and tracked using the Lagrangian particle tracking model.
At the end of the assigned larval duration, the particles' locations were used to define the 2-dimensional dispersal kernel.

'Release month' is used to explore the effect of adult spawning throughout the year. 'Release locations' were chosen to represent spawning on an array across and along the inner Georgia shelf (Fig. 1). 'Larval durations' represent a range observed for common reef fish in the area (Lindeman et al. 2000). 'Larval behavior' captures the effect of different vertical distributions on larval transport. Three simple behaviors were examined: fixed-depth deep, fixed-depth shallow and mid-depth passive vertical movement. These behaviors were chosen to maximize the difference in vertical distribution and thereby to evaluate the maximum effect of larval behavior. Finally, to represent subgridscale and other processes not included in the model, 3 'dispersion coefficients' were used in order to evaluate the effects of this 'eddy diffusion' or dispersion on larval dispersal: $K_{x}=K_{Y}=1.0,10.0$ and $50.0 \mathrm{~m}^{2} \mathrm{~s}^{-1}$. These values were chosen based on a comparison of the length scales of diffusion over time ( $\mathrm{h}$ to $\mathrm{mo}$ ) to apparent diffusivity $\left(K_{a}\right)$ reported in dye-diffusion studies summarized by Okubo (1971).

Data analysis. To quantify the effect of the 5 factors on the 2-dimensional dispersal kernels, we performed a multi-factor, multi-variable analysis of variance (MANOVA) using the ending positions of the particles released from each model run and the 50-50 MANOVA MATLAB code from Langsrud (2002). MANOVAs were calculated for 4 response variables: (1) each particles' ending position ( $x$ and $y$ location in the model), (2) each particles' ending distance and direction from the starting position, (3) the average ending distance $(d)$ and direction $(\theta)$ for all particles with the same parameter values, and (4) the principal variances $\left(s_{11}\right.$ and $s_{22}$ ) for all particles with the same parameter values. The MANOVA included both the 5 primary factors plus second-order interaction effects, and was not used to test for the significant effect of the various factors but to quantify the percent of the total variance explained by each factor.

Table 1. The 5 factors examined in the present study, with values used

\begin{tabular}{|lcc|}
\hline Factor & No. of values & Values \\
\hline $\begin{array}{l}\text { Release month } \\
\text { Release location }\end{array}$ & 12 & $\begin{array}{c}\text { Jan-Dec } \\
\text { Larval duration }\end{array}$ \\
Larval behavior & 3 & $\begin{array}{c}\text { onshore, offshore } \\
\text { onter, } 30,45 \mathrm{~d}\end{array}$ \\
Dispersion & 3 & $\begin{array}{c}\text { Surface-fixed; } \\
\text { deep-fixed; } \\
\text { mid-depth passive } \\
K=1,10,50 \mathrm{~m}^{2} \mathrm{~s}^{-1}\end{array}$ \\
\hline
\end{tabular}




\section{RESULTS}

\section{Description of dispersal kernels}

Larval dispersal from spawning on the Georgia shelf around GNRMS shows a strong seasonal pattern (Table 2, Fig. 2). During the summer months of June and July, when upwelling-favorable winds were predominant, particles were transported along-shelf to the northeast, and the distance dispersed was more than twice that of other seasons. In winter months (November, December, January, and February), net particle movement was along-shelf to the southwest and the size of the variance ellipse ( $m a j$ and $\mathrm{min}$ ) was greatest. Spring (March, April, and May) and autumn (August, September, and October) appeared to be transition seasons with generally reduced net onshore transport. In all releases, particles generally remained on the inner- and mid-shelf of the central southeast US continental shelf.

Differences among dispersal kernels for each of the release locations (Table 3, Fig. 3) generally reflected the structure in the monthly climatology flow fields, with particles generally traveling further in January and July. With the exception of the offshore releases, dispersal kernels were generally oriented along-shelf. The size of dispersal kernels were similar except for the on-shore release location, which tended to be elongated even further in the along-shore direction owing to larvae reaching the coast. As expected, both the mean distance dispersed $(d)$ and the spread (maj and min) of dispersal kernels increased with increasing larval duration (Table 4, Fig. 4). Dispersal was more isotropic for the $15 \mathrm{~d}$ larval duration with rounder

Table 2. Statistics of monthly 2-dimensional dispersal kernels. The 4 other parameters were set at center release location, 30 d larval duration, mid-depth passive behavior, and dispersion coefficient $(K)=10 \mathrm{~m}^{2} \mathrm{~s}^{-1}$; $d$ : distance from starting location; $\theta$ : direction from starting location; maj: major axis variance; min: minor axis variance; $\theta_{\mathrm{m}}$ : angle of major axis

\begin{tabular}{|lccccc|}
\hline Month & $\begin{array}{c}d \\
(\mathrm{~km})\end{array}$ & $\begin{array}{c}\theta \\
\left({ }^{\circ} \text { from E) }\right)\end{array}$ & $\begin{array}{c}\text { maj } \\
(\mathrm{km})\end{array}$ & $\begin{array}{c}\text { min } \\
(\mathrm{km})\end{array}$ & $\begin{array}{c}\theta_{\mathrm{m}} \\
\left({ }^{\circ} \text { from E) }\right.\end{array}$ \\
\hline Mar & 11 & 123 & 16 & 15 & -34 \\
Apr & 27 & 103 & 23 & 14 & 40 \\
May & 17 & 147 & 23 & 13 & 63 \\
Jun & 40 & 72 & 21 & 11 & 22 \\
Jul & 82 & 60 & 19 & 12 & 21 \\
Aug & 18 & 108 & 19 & 12 & 49 \\
Sep & 13 & 102 & 17 & 13 & 55 \\
Oct & 18 & -166 & 17 & 13 & 63 \\
Nov & 17 & -27 & 19 & 11 & -14 \\
Dec & 15 & -107 & 18 & 11 & 16 \\
Jan & 53 & -121 & 22 & 12 & 63 \\
Feb & 27 & 88 & 17 & 13 & 41 \\
& & & & & \\
\hline
\end{tabular}
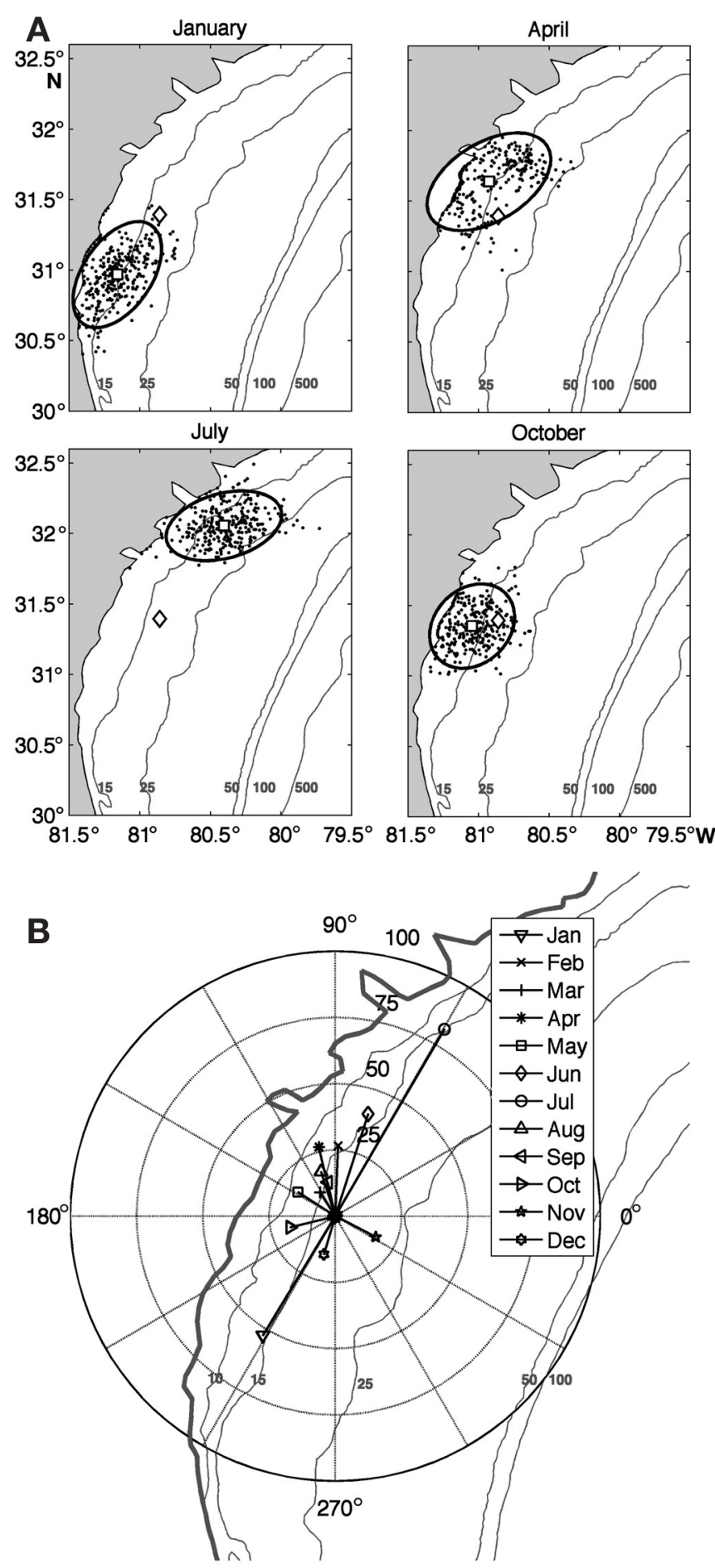

Fig. 2. (A) Ending position of passive particles released in Gray's Reef National Marine Sanctuary (GRNMS) in representative months (January, April, July and October) for each season. Also included are: mean starting location $(\diamond)$, mean ending location ( $\square$ ) and variance ellipse $(2 \sigma)$ from PCA (black ellipse). Isobaths (m) shown in gray. (B) Monthly mean dispersal distance and direction of particles released in GRNMS with dispersion coefficient $(K)=10 \mathrm{~m}^{2} \mathrm{~s}^{-1}$, duration $=30 \mathrm{~d}$, and passive particles released at mid-depth. Model coastline and isobaths $(\mathrm{m})$ shown in gray 
Table 3. Statistics of 2-dimensional dispersal kernels for particles released at each of the 5 locations for representative months. The 3 other parameters were set at $30 \mathrm{~d}$ larval duration, mid-depth passive behavior, and dispersion coefficient $(K)=10 \mathrm{~m}^{2} \mathrm{~s}^{-1} ; d$ : distance from starting location; $\theta$ : direction from starting location; maj: major axis variance; min: minor axis variance; $\theta_{\mathrm{m}}$ : angle of major axis. GRNMS: Gray's Reef National Marine Sanctuary

\begin{tabular}{|c|c|c|c|c|c|c|}
\hline Month & Location & $\begin{array}{c}d \\
(\mathrm{~km})\end{array}$ & $\begin{array}{c}\theta \\
\left({ }^{\circ} \text { from E) }\right)\end{array}$ & $\begin{array}{l}\text { maj } \\
(\mathrm{km})\end{array}$ & $\begin{array}{l}\min \\
(\mathrm{km})\end{array}$ & $\begin{array}{c}\theta_{\mathrm{m}} \\
\left({ }^{\circ} \text { from E) }\right.\end{array}$ \\
\hline \multirow[t]{5}{*}{ Jan } & GRNMS & 52 & -121 & 21 & 12 & 63 \\
\hline & Onshore & 92 & -100 & 29 & 11 & -84 \\
\hline & Offshore & 20 & 150 & 22 & 12 & 20 \\
\hline & North & 32 & -156 & 19 & 12 & 41 \\
\hline & South & 35 & -88 & 20 & 11 & 65 \\
\hline \multirow[t]{5}{*}{ Apr } & GRNMS & 27 & 103 & 23 & 14 & 40 \\
\hline & Onshore & 12 & 95 & 23 & 11 & 57 \\
\hline & Offshore & 21 & 87 & 22 & 11 & 6 \\
\hline & North & 22 & 46 & 21 & 13 & -80 \\
\hline & South & 13 & 56 & 15 & 13 & 21 \\
\hline \multirow[t]{5}{*}{ Jul } & GRNMS & 82 & 60 & 19 & 12 & 21 \\
\hline & Onshore & 79 & 60 & 28 & 9 & 38 \\
\hline & Offshore & 96 & 51 & 28 & 11 & 5 \\
\hline & North & 84 & 40 & 16 & 13 & 6 \\
\hline & South & 79 & 70 & 19 & 12 & 35 \\
\hline \multirow{5}{*}{ Oct } & GRNMS & 17 & -166 & 17 & 13 & 63 \\
\hline & Onshore & 27 & 60 & 28 & 9 & 38 \\
\hline & Offshore & 12 & 138 & 19 & 13 & -16 \\
\hline & North & 17 & 106 & 18 & 13 & 66 \\
\hline & South & 6 & -126 & 17 & 13 & 53 \\
\hline
\end{tabular}

dispersal kernels (as evidenced by the relative sizes of maj and min). The dispersal ellipse changes shape to reflect that along-shelf currents were generally stronger than cross-shelf currents, the along-coast current shear, and the arrival of larvae at the coastline.

The effect of the 3 simple larval behaviors on the dispersal kernels was relatively small (Table 5, Fig. 5). The mean distance dispersed $(d)$ of the surface behavior was generally offshore of the mid-depth and deep behavior, while the mean dispersal distance $(d)$ of the deep behavior was generally on-shore of the others. In January and July, those particles assigned to the surface behavior were dispersed the largest distances. The mean dispersal distance for October and April was much smaller at all depths, and with very little difference observed among behaviors.

As expected, eddy diffusion had a large effect on the principal variances (maj and $\mathrm{min}$ ) of the dispersal kernels and a small effect on mean dispersal distance and direction (Table 6, Fig. 6). With $K=1$ and $10 \mathrm{~m}^{2} \mathrm{~s}^{-1}$, all of the particles end up in a relatively small areas, with very similar mean distance dispersed and similar direction of dispersal. The variance ellipses of the resulting dispersal kernels were relatively small. However, with $K=50 \mathrm{~m}^{2} \mathrm{~s}^{-1}$, articles were advected in
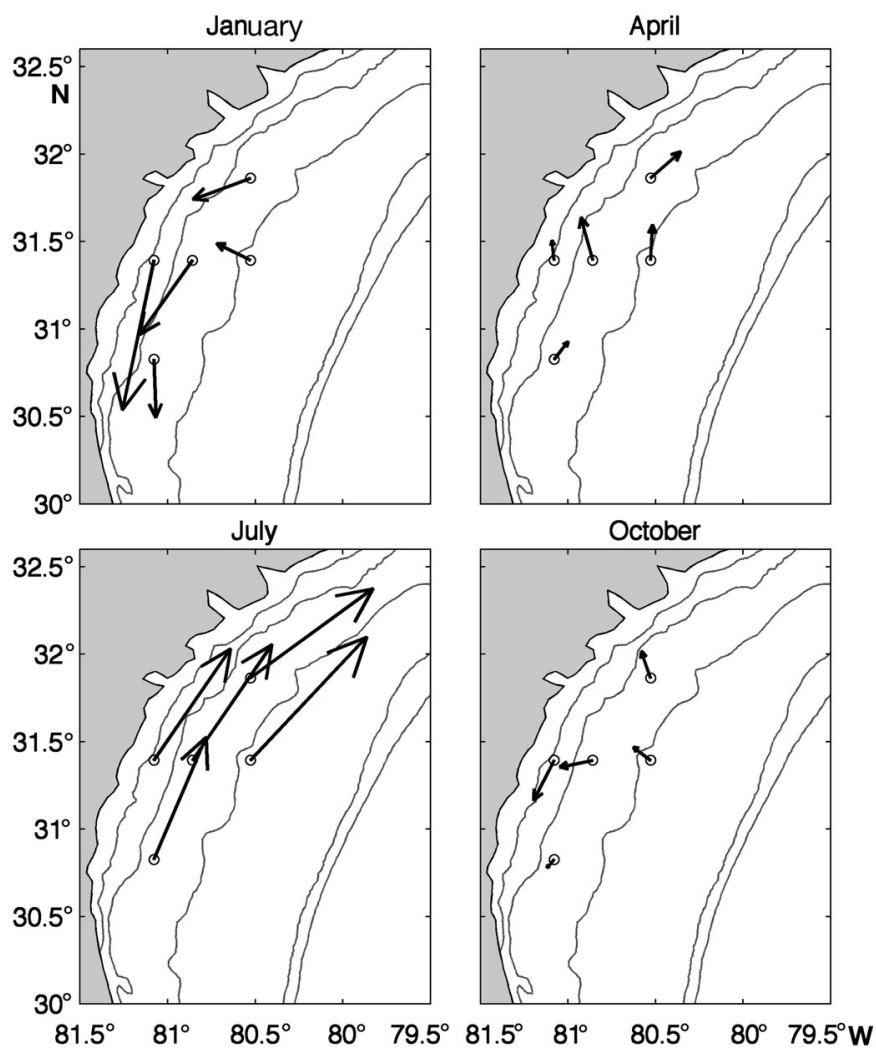

Fig. 3. Mean ending position of all passive particles released in the representative month of each season on the southeast US continental shelf in Gray's Reef National Marine Sanctuary (GRNMS), and locations north, south, onshore and offshore of GRNMS. Arrows point from the starting position of all particles to the center of the ending position; 10, 15, 25, 50 and $100 \mathrm{~m}$ isobaths are shown

Table 4. Statistics of 2-dimensional dispersal kernels for particles with different larval durations released in January, April, July and October. The 3 other parameters were set at center release location, mid-depth passive behavior, and dispersion coefficient $(K)=10 \mathrm{~m}^{2} \mathrm{~s}^{-1} ; d$ : distance from starting location; $\theta$ : direction from starting location; maj: major axis variance; min: minor axis variance; $\theta_{\mathrm{m}}$ : angle of major axis

\begin{tabular}{|lcccccc|}
\hline \multirow{4}{*}{ Month } & $\begin{array}{c}\text { Duration } \\
(\mathrm{d})\end{array}$ & $\begin{array}{c}d \\
(\mathrm{~km})\end{array}$ & $\begin{array}{c}\theta \\
\left({ }^{\circ} \text { from E) }\right.\end{array}$ & $\begin{array}{c}\text { maj } \\
(\mathrm{km})\end{array}$ & $\begin{array}{c}\text { min } \\
(\mathrm{km})\end{array}$ & $\begin{array}{c}\theta_{\mathrm{m}} \\
\left({ }^{\circ} \text { from E) }\right.\end{array}$ \\
\hline Jan & 15 & 23 & -134 & 12 & 9 & 52 \\
& 30 & 53 & -121 & 22 & 12 & 63 \\
& 45 & 78 & -113 & 30 & 14 & 76 \\
Apr & 15 & 19 & 130 & 14 & 10 & 76 \\
& 30 & 27 & 103 & 23 & 14 & 40 \\
& 45 & 32 & 85 & 30 & 16 & 25 \\
Jul & 15 & 40 & 68 & 12 & 9 & 27 \\
& 30 & 82 & 60 & 19 & 12 & 21 \\
& 45 & 123 & 52 & 27 & 15 & 16 \\
& 15 & 11 & -176 & 11 & 10 & 54 \\
& 30 & 18 & -166 & 17 & 13 & 63 \\
& 45 & 24 & -159 & 24 & 16 & 69 \\
\hline
\end{tabular}


Table 5. Statistics of 2-dimensional dispersal kernels for particles with different larval behaviors released in January, April, July and October. Surf-fixed: fixed depth surface; Mid-passive: mid-depth passive; Deep-fixed: fixed depth deep. The 3 other parameters were set at center release location, $30 \mathrm{~d}$ larval duration, and dispersion coefficient $(K)=10 \mathrm{~m}^{2} \mathrm{~s}^{-1} ; d$ : distance from starting location; $\theta$ : direction from starting location; maj: major axis variance; $\min$ : minor axis variance; $\theta_{\mathrm{m}}$ : angle of major axis

\begin{tabular}{|ccccccc|}
\hline Month Behavior & $\begin{array}{c}d \\
(\mathrm{~km})\end{array}$ & $\begin{array}{c}\theta \\
\left({ }^{\circ} \text { from E) }\right)\end{array}$ & $\begin{array}{c}\text { maj } \\
(\mathrm{km})\end{array}$ & $\begin{array}{c}\text { min } \\
(\mathrm{km})\end{array}$ & $\begin{array}{c}\theta_{\mathrm{m}} \\
\left({ }^{\circ} \text { from E) }\right.\end{array}$ \\
\hline Jan & Surf-fixed & 66 & -108 & 26 & 10 & 61 \\
& Mid-passive & 53 & -121 & 22 & 12 & 63 \\
& Deep-fixed & 41 & -128 & 20 & 10 & 58 \\
Apr & Surf-fixed & 20 & 95 & 25 & 16 & 52 \\
& Mid-passive & 27 & 103 & 23 & 14 & 40 \\
& Deep-fixed & 33 & 110 & 18 & 10 & 49 \\
& Surf-fixed & 97 & 54 & 17 & 13 & 14 \\
& Mid-passive & 82 & 60 & 19 & 12 & 21 \\
& Deep-fixed & 69 & 67 & 17 & 12 & 39 \\
& Surf-fixed & 19 & -112 & 18 & 13 & 40 \\
& Mid-passive & 18 & -166 & 17 & 13 & 63 \\
& Deep-fixed & 20 & 170 & 17 & 10 & 69 \\
& & & & & & \\
\hline
\end{tabular}

a variety of directions and over a broad range of dispersal distances. This large variance in individual direction and distance resulted in a smaller mean dis-

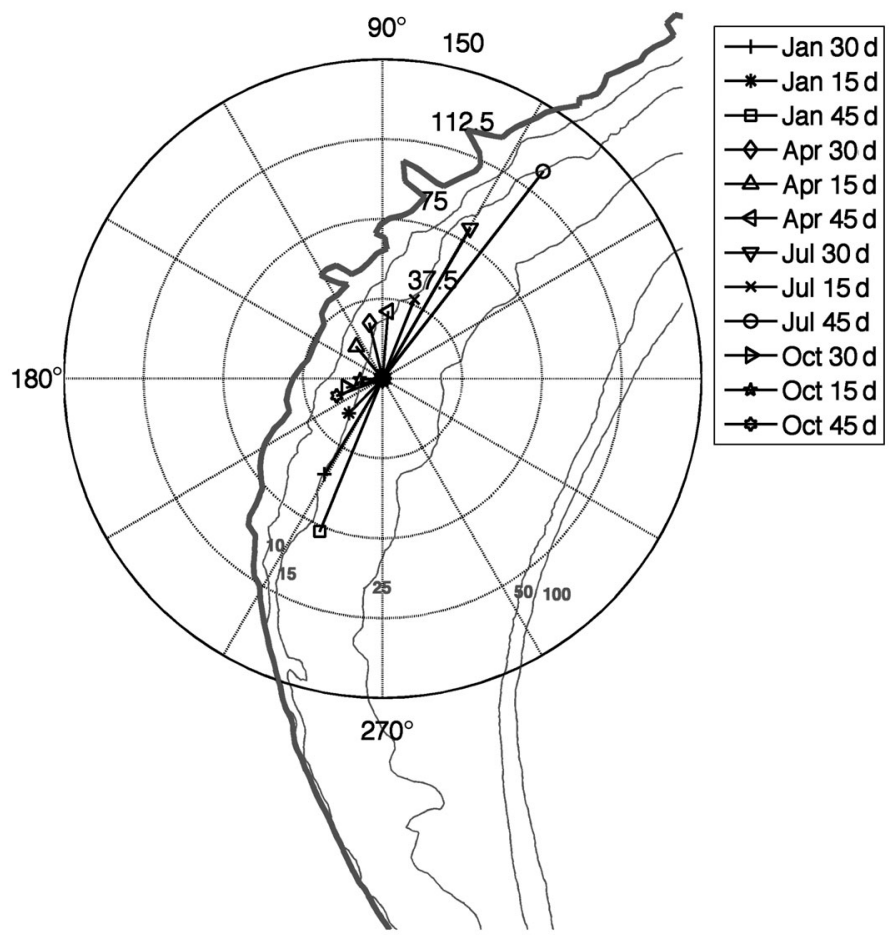

Fig. 4. Monthly mean dispersal distance and direction of particles released in Gray's Reef National Marine Sanctuary (GRNMS) with the dispersion coefficient $(K)=10 \mathrm{~m}^{2} \mathrm{~s}^{-1}$, duration $=15,30$ and $45 \mathrm{~d}$, and passive particles released at middepth. Model coastline and 10, 15, 25, 50 and $100 \mathrm{~m}$ isobaths shown in gray
Table 6. Statistics of 2-dimensional dispersal kernels for releases made in January, April, July and October using different dispersion coefficients. The 3 other parameters were set at center release location, $30 \mathrm{~d}$ larval duration, and middepth passive behavior; $K$ : dispersion coefficient; $d$ : distance from starting location; $\theta$ : direction from starting location; maj: major axis variance; min: minor axis variance; $\theta_{\mathrm{m}}$ : angle of major axis

\begin{tabular}{|lccrrrr|}
\hline Month & $\begin{array}{c}K \\
\left(\mathrm{~m}^{2} \mathrm{~s}^{-1}\right)\end{array}$ & $\begin{array}{c}d \\
(\mathrm{~km})\end{array}$ & $\begin{array}{c}\theta \\
\left({ }^{\circ} \text { from E) }\right)\end{array}$ & $\begin{array}{c}\text { maj } \\
(\mathrm{km})\end{array}$ & $\begin{array}{c}\text { min } \\
(\mathrm{km})\end{array}$ & $\begin{array}{c}\theta_{\mathrm{m}} \\
\left({ }^{\circ} \text { from E) }\right.\end{array}$ \\
\hline Jan & 1 & 54 & -121 & 7 & 3 & 54 \\
& 10 & 53 & -121 & 22 & 12 & 63 \\
& 50 & 33 & -127 & 38 & 24 & 72 \\
Apr & 1 & 40 & 96 & 13 & 6 & 14 \\
& 10 & 27 & 103 & 23 & 14 & 40 \\
& 50 & 18 & 96 & 33 & 26 & 42 \\
Jul & 1 & 82 & 61 & 6 & 5 & 14 \\
& 10 & 82 & 60 & 19 & 12 & 21 \\
& 50 & 71 & 58 & 50 & 22 & 24 \\
Oct & 1 & 23 & -158 & 6 & 5 & 72 \\
& 10 & 18 & -166 & 17 & 13 & 63 \\
& 50 & 8 & 170 & 31 & 27 & 61 \\
\hline
\end{tabular}

persal distance $d$ and larger variance ellipses. To determine the appropriate value of eddy diffusion in our study, we compared the length scales of diffusion resulting from the 3 values of $K\left(1,10\right.$, and $\left.50 \mathrm{~m}^{2} \mathrm{~s}^{-1}\right)$ with the results of dye studies summarized by Okubo (1971). When averaging over all months, $K=10 \mathrm{~m}^{2} \mathrm{~s}^{-1}$ provides the best match with a length scale of approximately $100 \mathrm{~km}$ after $30 \mathrm{~d}$.

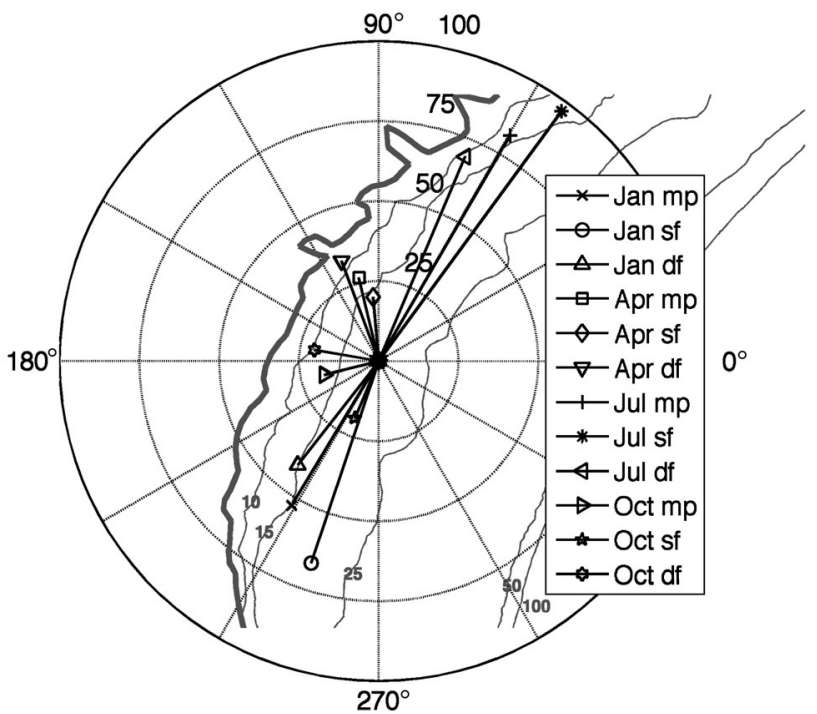

Fig. 5. Monthly mean dispersal distance and direction of particles released in Gray's Reef National Marine Sanctuary (GRNMS) with dispersion coefficient $(K)=10 \mathrm{~m}^{2} \mathrm{~s}^{-1}$, duration $=30 \mathrm{~d}$, and 3 behaviors: passive particles at mid-depth (mp), surface-fixed (sf), and deep-fixed (df). Model coastline and $10,15,25,50$ and $100 \mathrm{~m}$ isobaths shown in gray 


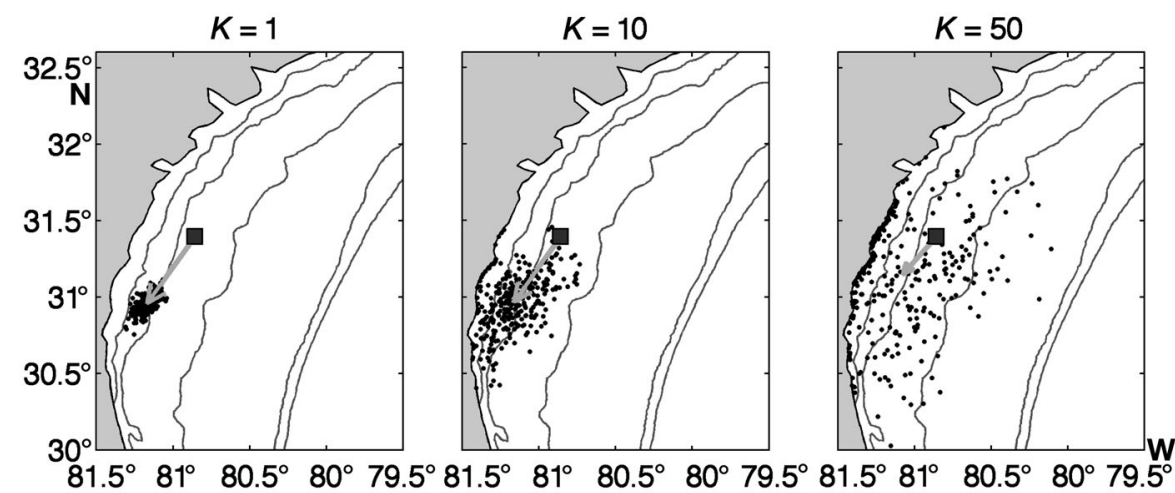

Fig. 6. Ending positions of particles released in Gray's Reef National Marine Sanctuary (GRNMS) in January for each of the different dispersion coefficients, $K\left(\mathrm{~m}^{2} \mathrm{~s}^{-1}\right)$. Gray arrows point to the mean ending location of all drifters

of variance explained. Results were similar for the mean distance and direction, with release time and the interaction between release time and release location explaining more than $50 \%$ of the variability.

Of the remaining 3 factors, larval duration exhibited moderate influence on the individual distance and direction, the mean distance and direction, and the variance of the dispersal kernels. This factor accounted for between 7 and $10 \%$ of the variance in these dispersal kernel parameters. As explained above, dispersal distance increased as larval duration increased, direction became more variable, and the variance

\section{Quantification of effects on dispersal kernels}

From the MANOVA analysis, release location and release month had the greatest effect on the 2-dimensional dispersal kernels. Release location explained almost half of the variance in the ending locations of individual particles (Table 7). However, only a small percentage of the variance was explained by release location when individual distance and direction were used as the response variable. This suggests that particles from different release locations were advected in a similar manner, and thus that their distance and direction were similar even though their ending locations differed. Release time (or month) explained more variability than other factors in individual distance and direction, and the interaction between release time and location was ranked second in terms ellipse grew. The interaction between release time and larval duration explained an addition 2 to $3 \%$ of the varaince in the dispersal kernel statistics. Larval behavior had minimal effects on the dispersal kernel statistics. At most, larval behavior accounted for $2.2 \%$ of the variance in the dispersal kernels. This result is surprising given that the behaviors were choosen to maximize their effect on larval dispersal. Finally, the dispersion coefficient $\left(K_{x}\right.$ and $K_{y}$ ) had a dominant effect on the variance ellipse of the dispersal kernel (see Fig. 6), accounting for $70 \%$ of the variance. Dispersion had almost no effect on the other dispersal kernel statistics.

The unexplained portion of the variance (the 'Error' row in Table 7 ) ranged from a low of $5.3 \%$ in the variance ellipse parameters to a high of $54.7 \%$ in distance/direction for all individual particles.

Table 7. Results of a multi-factor, multi-variable analysis of variance (MANOVA) with 4 sets of response variables: (1) ending location of individual particles, (2) distance/direction from the release point of individual particles, (3) mean distance/direction from release point, and (4) variance ellipse parameters. Percentages represent the amount of variance in the response variable that is explained by each factor. All primary factors plus any second-order interaction effects of $>1.0 \%$ are included

\begin{tabular}{|c|c|c|c|c|c|c|}
\hline \multirow{2}{*}{ Factor } & \multicolumn{3}{|c|}{ - Individual- } & \multirow[b]{2}{*}{$\mathrm{df}$} & \multirow{2}{*}{$\begin{array}{c}\text { Mean } \\
\text { Distance/ } \\
\text { Direction (\%) }\end{array}$} & \multirow[b]{2}{*}{$\begin{array}{c}\text { Variance } \\
(\%)\end{array}$} \\
\hline & df & $\begin{array}{c}\text { Location } \\
\text { (\%) }\end{array}$ & $\begin{array}{c}\text { Distance/ } \\
\text { Direction (\%) }\end{array}$ & & & \\
\hline Month & 11 & 16.3 & 19.1 & 11 & 36.1 & 0.1 \\
\hline Release location & 4 & 45.6 & 2.4 & 4 & 4.4 & 1.7 \\
\hline Larval duration & 2 & 1.5 & 7.3 & 2 & 9.0 & 10.6 \\
\hline Larval behavior & 2 & 1.0 & 1.1 & 2 & 2.2 & 0.9 \\
\hline Dispersion & 2 & 0.0 & 1.5 & 2 & 0.4 & 70.5 \\
\hline Month $\times$ Release location & 44 & 4.5 & 8.2 & 44 & 19.5 & 1.1 \\
\hline Month $\times$ Dispersion & 22 & 0.2 & 1.1 & 22 & 1.1 & 1.0 \\
\hline Month $\times$ Duration & 22 & 2.7 & 2.3 & 22 & 3.9 & 0.4 \\
\hline Release location $\times$ Dispersion & 8 & 0.7 & 0.0 & 8 & 0.7 & 1.7 \\
\hline Other & & 0.4 & 2.3 & & 3.7 & 6.7 \\
\hline Error & 80978 & 27.1 & 54.7 & 1452 & 19.0 & 5.3 \\
\hline
\end{tabular}




\section{DISCUSSION}

This study provides a baseline in quantifying and understanding larval dispersal on the inner- and midshelf of the central southeast US continental shelf. The fine-scale structure in the climatology flow fields is evident in the resulting dispersal kernels from the 5 release locations tested. As expected, the dispersal kernels on the inner- and mid-continental shelves off the coast of Georgia show a strong seasonal pattern in relation to the seasonal pattern in the circulation and winds (as described in 'Study region' above). The use of 2-dimensional dispersal kernels in this study allowed the exploration of the interactions among the biological and physical parameters of interest. In addition to the parameters being tested in this study, 2dimensional dispersal kernels could be used to study a range of biological hypotheses such as the importance to populations of retention versus dispersal, larval success in arriving at potential settlement habitats, and the role of density-dependent processes such as the overlap of larvae with potential prey or predators. While we have not considered any specific species, our results indicated that spawning time and location play a dominant role in shaping dispersal kernels in this region, suggesting that more attention should be given to the role of adult behavior in determining planktonic dispersal.

The results of the MANOVA indicate that release month and location are the main factors that explaining the dispersal of particles in this region. To a lesser extent, larval duration and behavior are also important. The relatively simple larval behaviors included in our model were chosen to examine the maximum effect that behavior can have on larval transport. On the inner shelf in shallow water, the top and bottom Ekman layers may be merged (Austin \& Lentz 2002) causing the water column to move largely as a slab and resulting in very little difference in dispersal owing to either larval position in the water column or behavior. For this region of the shelf, adult spawning behavior may be more important than larval behavior in that the adults spawn in innerand mid-shelf regions that are largely retentive. Larval behavior may also be more important for species that spawn further offshore in the deeper water and want to remain on the shelf, or for those species linking behavior to tidal cues resulting in net cross-shelf transport. Fig. 7 provides the results for January larvae released at the $60 \mathrm{~m}$ isobath directly offshore from GRNMS. In this case, behavior matters and surface particles (black) are advected on-shelf, while the deep particles (light gray) are advected off-shelf. The pas- sive, mid-depth particles (medium gray) are advected the furthest and move generally along-shelf to the north.

A second explanation of the relatively low importance of larval behavior is our use of the long-term monthly mean flow fields. One consequence of using the long-term monthly mean velocity fields is that, by definition, we will miss any transient features such as fronts, eddies, and other time-varying features of the circulation that might increase the importance of larval behavior in dispersal. Edwards et al. (2006) provided a look at the barotropic circulation in this region during observed drifter release periods throughout 2000 and 2001. However, the use of the long-term mean flow fields used herein provides an important first measure for the dispersal of larvae on the southeast US continental shelf and a description of the mean dispersal of particles released on the Georgia shelf, about which variations (shorter and longer time scales) can be assessed.

With the mean dispersal estimated, we can begin to look at interannual variability in reference to this mean state and to include more realistic behaviors, both adult spawning and larval behaviors. Field and laboratory experiments (Forward et al. 1999) have

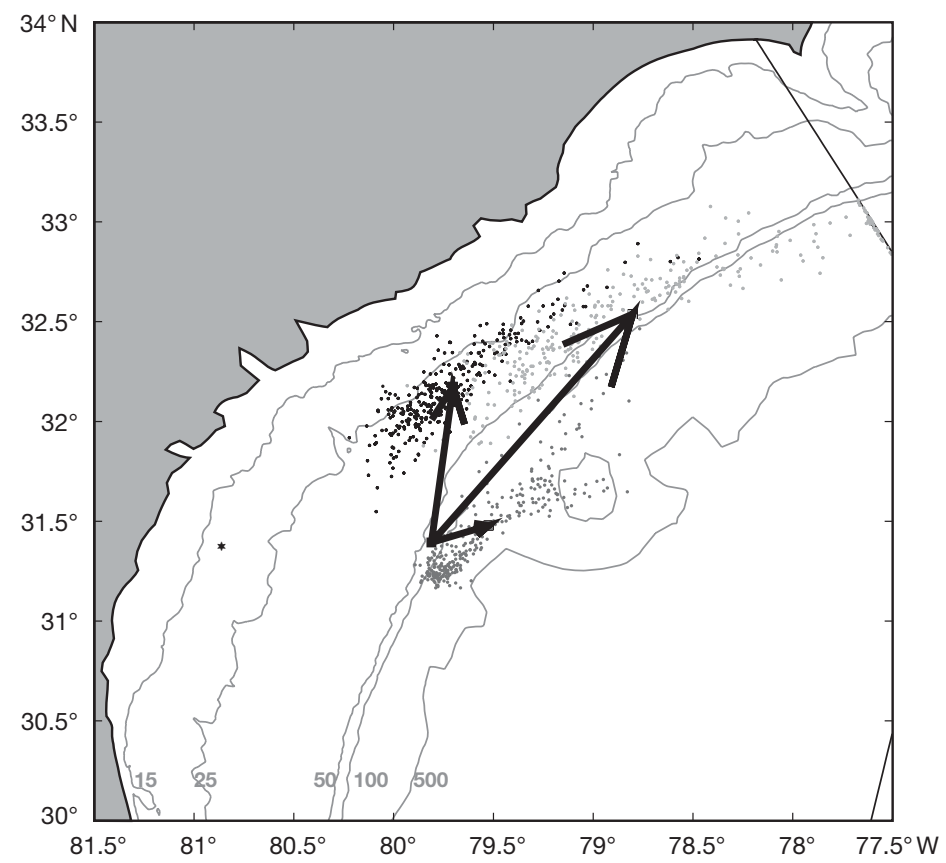

Fig. 7. Ending position of particles released at a location directly offshore of Gray's Reef National Marine Sanctuary (GRNMS, ${ }^{*}$ ) at the $60 \mathrm{~m}$ isobath for each of the 3 larval behaviors. Black squares: surface-fixed particles; medium gray squares: mid-depth passive particles; light gray squares: deep particles at a fixed depth above the bottom. Arrows point from the starting location of all particles to the center of the ending position of each behavior. Diagonal line in upper and lower right-hand corners mark end of model domain 
found evidence of more complicated behaviors in larval fish. Hare et al. (1999) modeled menhaden and spot larval transport on the northern part of the southeast US continental shelf using behaviors that changed ontogenetically as the larvae moved through the egg, yolk-sac, and other larval stages. Vertical migration can result in fundamentally different advective pathways. Recent modeling studies used adaptations and extensions of a basic algorithm for advecting large numbers of individual organisms to include specific combinations of dispersion (vertical and horizontal) via random flight superposed on the advection (Werner et al. 2001) and larval behavior (Werner et al. 1993, Hare et al. 1999). In the present study, we explicitly included only horizontal dispersion. As with the horizontal turbulent diffusivity, the hydrodynamic model includes vertical turbulence, and we did not include any additional vertical turbulence in the particle tracking model. With a $1 \mathrm{~h}$ time step and assumed larval swimming speeds of around 1 body length per second, the larvae should generally be able to determine their vertical position in the water column (Werner et al. 2001). Our next step is to provide a realistic assessment of larval dispersal of black sea bass by combining interannual variability with adult (spawning time and location) and larval (active vertical migration with ontogenetic change) behavior.

The results of this research have broad implications for our understanding of the importance of adult behavior-in the form of spawning time and location - versus larval behavior to the outcome of larval transport, settlement and, ultimately, connectivity in marine populations. Fish species show a great variety in spawning patterns, and one hypothesis by which to explain this variation is that reproductive patterns are driven by larval requirements and maximize larval recruitment (Robertson 1991). Many species spawn in large aggregations whereby populations migrate to specific locations at specific times of the year to spawn (Domeier \& Colin 1997, Sedberry et al. 2006). In the North Sea, adult plaice migrate long distances to spawn in specific areas that are located upstream of the nursery grounds used by juvenile fish (Harding et al. 1978). Other species have been found to spawn over long periods throughout a broad region (Sedberry et al. 2006). Owing to the highly retentive nature of the inner- and mid-shelf, adult spawning in this region supports the hypothesis of the selection of spawning behavior to maximize larval recruitment. This implies a greater need to protect the spawning habitats of fish species in this region. On a larger scale, e.g. in the study of population connectivity of mobile species, attention should be focused on the time and place of spawning as well as the dispersal of pelagic larvae.
Acknowledgements. Funding from SEACOOS, Office of Naval Research Award N00014-02-1-0972, and a contract from the Center for Coastal Fisheries and Habitat Research to the University of North Carolina Chapel Hill from funds provided by the Office of National Marine Sanctuaries (NOAA NOS) in support of research at Gray's Reef National Marine Sanctuary is gratefully acknowledged. We also thank Dr. David Mountain, Dr. Greg Lough and 3 anonymous reviewers for their review and comments on the manuscript.

\section{LITERATURE CITED}

Arnold WS, Hitchcock GL, Frischer ME, Wanninkhof R, Sheng YP (2005) Dispersal of an introduced larval cohort in a coastal lagoon. Limnol Oceanogr 50:587-597

Austin JA, Lentz SJ (2002) The inner shelf response to winddriven upwelling and downwelling. J Phys Oceanogr 32: 2171-2193

Bailey KM, Houde ED (1989) Predation on eggs and larvae of marine fishes and the recruitment problem. Adv Mar Biol 25:1-67

Berg HC (1993) Random walks in biology. Princeton University Press, Princeton, NJ

Blanton JO, Schwing FB, Weber AH, Pietrafesa LJ, Hayes DW (1985) Wind stress climatology in the South Atlantic Bight. In: Atkinson LP, Menzel DW, Bush KA (eds) Oceanography of the southeastern U. S. continental shelf. American Geophysical Union, Washington, DC, p 10-22

Blanton BO, Aretxabaleta A, Werner FE, Seim HE (2003) Monthly climatology of the continental shelf waters of the South Atlantic Bight. J Geophys Res 108:C83264, doi: 10.1029/2002JC001609

Blanton BO, Werner FE, Seim HE, Luettich RA Jr and others (2004) Barotropic tides in the South Atlantic Bight. J Geophys Res 109:C12024, doi: 10.1029/2004JC002455

Boicourt WC, Wiseman WJ Jr, Valle-Levinson A, Atkinson LP (1998) Continental shelf of the southeastern United States and the Gulf of Mexico: in the shadow of the western boundary current. In: Robinson AR, Brink KH (eds) The sea, Vol 11. John Wiley \& Sons, New York, p 135-182

Caley MJ, Carr MH, Hixon MA, Hughes TP, Jones GP, Menge BA (1996) Recruitment and the local dynamics of open marine populations. Annu Rev Ecol Syst 27:477-500

Cowen RK, Hare JA, Fahay MP (1993) Beyond hydrography: Can physical processes explain larval fish assemblages within the Middle Atlantic Bight. Mar Ecol Prog Ser 53: 567-587

Cowen RK, Paris CB, Srinivasan A (2006) Scaling of connectivity in marine populations. Science 311:522-527

Domeier ML, Colin PL (1997) Tropical reef fish spawning aggregations: defined and reviewed. Bull Mar Sci 60: $698-726$

Edwards KP, Hare JA, Werner FE, Blanton BO (2006) Lagrangian circulation on the southeast U.S. continental shelf: implications to larval dispersal and retention. Cont Shelf Res 26:1375-1394

Forward RB Jr, Vries MCD, Tankersley RA, Rittschof R, Hettler WF, Burke JS, Welsch JM, Hoss DE (1999) Behaviour and sensory physiology of Atlantic menhaden larvae, Brevoortia tyrannus, during horizontal transport. Fish Oceanogr 8:37-56

Grantham BA, Eckert GL, Shanks AL (2003) Dispersal potential of marine invertebrates in diverse habitats. Ecol Appl 13:S108-S116

Greenberg DA, Werner FE, Lynch DR (1998) A diagnostic finite-element ocean circulation model in spherical-polar coordinates. J Atmos Ocean Technol 15:942-958 
Guichard F, Levin SA, Hastings A, Siegel D (2004) Toward a dynamic metacommunity approach to marine reserve theory. BioScience 54:1003-1011

Harding D, Nichols JH, Tungate DS (1978) The spawning of plaice (Pleuronectes platessa) in the southern North Sea and the English Channel. Rapp P-V Reun Cons Int Explor Mer 172:102-113

Hare JA (2005) The use of early life stages in stock identification studies. In: Cardin S, Friedland K, Waldman J (eds) Stock identification methods. Academic Press, New York, p 89-117

Hare JA, Walsh HJ (2007) Planktonic linkages among marine protected areas on the south Florida and southeast United States continental shelf. Can J Fish Aquat Sci 64:1234-1247

Hare JA, Quinlan JA, Werner FE, Blanton BO, Govoni JJ, Forward RB, Settle LR, Hoss DE (1999) Larval transport during winter in the SABRE study area: results of a coupled vertical larval behaviour-three-dimensional circulation model. Fish Oceanogr 8:57-76

Hunter JR, Craig PD, Phillips HE (1993) On the use of random walk models with spatially variable diffusivity. J Comput Phys 106:366-376

Kinlan BP, Gaines SD (2003) Propagule dispersal in marine and terrestrial environments: a community perspective. Ecology 84:2007-2020

Langsrud O (2002) 50-50 multivariate analysis of variance for collinear responses. J R Stat Soc D (The Statistician) 51(3): 305-317

Lindeman KC, Pugliese R, Waugh GT, Ault JS (2000) Developmental patterns within a multispecies reef fishery: management applications for essential fish habitats and protected areas. Bull Mar Sci 66:929-956

Lynch DR, Werner FE (1991) Three-dimensional hydrodynamics on finite elements: I. Linearized harmonic model. Int J Num Methods Fluids 12:507-533

Nathan R (2001) The challenges of studying dispersal. Trends Ecol Evol 16:481-483

Okubo A (1971) Oceanic diffusion diagrams. Deep-Sea Res 18:789-802

Olson RR (1985) The consequences of short-distance larval

Editorial responsibility: Howard Browman (Associate Editorin-Chief), Storebø, Norway dispersal in a sessile marine invertebrate. Ecology 66: 30-39

Paris CB, Cowen RK, Claro R, Lindeman KC (2005) Larval transport pathways from Cuban snapper (Lutjanidae) spawning aggregations based on bio-physical modeling. Mar Ecol Prog Ser 296:93-106

Pedersen OP, Aschan M, Rasmussen T, Tande KS, Slagstad D (2003) Larval dispersal and mother populations of Pandalus borealis investigated by a Lagrangian particletracking model. Fish Res 65:173-190

Preisendorfer RW (1988) Principal component analysis in meteorology and oceanography. Elsevier Science, Amsterdam

Robertson DR (1991) The role of adult biology in the timing of spawning of tropical reef fishes. In: Sale PF (ed) The ecology of fishes on coral reefs. Academic Press, San Diego, CA, p 356-386

Sedberry GR, Pashuk O, Wyanski DM, Stephen JA, Weinback P (2006) Spawning locations for Atlantic reef fisheries off the southeastern US. Proc Gulf Caribb Fish Inst $57: 463-514$

Shanks AL, Grantham BA, Carr MH (2003) Propagule dispersal distance and the size and spacing of marine reserves. Ecol Appl 13:S159-S169

Siegel DA, Kinlan BP, Gaylord B, Gaines SD (2003) Lagrangian descriptions of marine larval dispersion. Mar Ecol Prog Ser 260:83-96

Thorrold SR, Jones GP, Hellberg ME, Burton RS, Swearer SE, Neigel JE, Morgan SG, Warner RR (2002) Quantifying larval retention and connectivity in marine populations with artificial and natural markers. Bull Mar Sci 70(Suppl 1):291-308

Werner FE, Page FH, Lynch DR, Loder JW, Lough RG, Perry RI, Greenberg DA, Sinclair MM (1993) Influences of mean advection and simple behavior on the distribution of cod and haddock early life stages on Georges Bank. Fish Oceanogr 2:1793-1822

Werner FE, Mackenzie BR, Perry RI, Lough RG, Naimie CE, Blanton BO, Quinlan JA (2001) Larval trophodynamics, turbulence and drift on Georges Bank: a sensitivity analysis of cod and haddock. Sci Mar 65(Suppl 1):99-115

Submitted: February 8, 2007; Accepted: July 20, 2007

Proofs received from author(s): December 6, 2007 